\title{
Manage With Me 1.0; metodologia lúdica no processo de ensino
}

Isamara de Melo Dantas Bezerra (Instituto Federal de Educação, Ciência e Tecnologia do Rio Grande do Norte, IFRN) isamaradantass@gmail.com

\section{Resumo}

Organizações buscam cada vez mais introduzir metodologias que aprimorem seus processos produtivos, proporcionando uma maior fluidez no mercado consumidor. A partir desta perspectiva, se faz necessário o investimento em metodologias ativas de ensino, buscando potencializar o aprimoramento de habilidades dos futuros profissionais. O Manage With Me 1.0, consiste em uma simulação realista, que busca desenvolver e aprimorar a capacidade dos jogadores realizarem as atividades contidas em um almoxarifado, de forma lúdica. O presente trabalho tem como objetivo contribuir para o aperfeiçoamento dos jogadores e para a formação de novos profissionais com maior entendimento do almoxarifado e as práticas realizadas para o seu gerenciamento. Foram utilizadas metodologias ativas, visto que contribuem com efeitos positivos no processo de ensino-aprendizagem. O contato com a problemática desperta nos jogadores o interesse em solucionar os conflitos e ultrapassar os obstáculos apresentados no jogo. A elaboração do Manage With Me 1.0 resultou em um jogo totalmente flexível, podendo integrar futuramente novas disciplinas que estejam presentes na grade curricular do grupo de discentes que o joguem, possibilitando sua utilização em outras áreas.

Palavras-Chaves: Metodologia, Almoxarifado, Gerenciamento, Jogo e Prática lúdica

\section{Introdução}

A excelência de uma organização é resultado da sua capacidade de desempenho e planejamento. O que de fato lhes é necessário para superar obstáculos encontrados diariamente na vida entre corporações e fornecer seus serviços com exímio. Para atingir a excelência e prestar seus serviços com êxito, todos as partes que compõe a organização devem funcionar plenamente.

Porém o funcionamento pleno total de uma organização ainda é algo utópico, sempre havendo mesmo que mínimas falhas e erros em seus processos internos, o ideal é buscar se aproximar o máximo possível da perfeição. Grande exemplo de que este pensamento ainda 
não se é alcançado é o almoxarifado de uma organização, local onde ocorre diversos processos importantes para a empresa.

Segundo Araújo (2018) sempre que pensamos em um almoxarifado, imaginamos um local espaçoso, cheio de objetos, bem organizado e com pessoas devidamente capacitadas e apitas executando tarefas integradas e seguras. Porém isso não ocorre em todos os casos, na qual o almoxarifado se torna um local onde os produtos e materiais estocados se tornam obsoletos, sem se dar conta da dimensão do prejuízo causado a empresa.

As organizações buscam a introdução de novas metodologias que lhes proporcionem o aprimoramento dos seus processos logísticos, se tornando cada vez mais eficiente em seu mercado. Visualizando esta perspectiva, o investimento em metodologias ativas de ensino tem se tornado cada vez maior, buscando aprimorar as habilidades dos futuros profissionais.

Segundo Barbosa et al [2018] ferramentas como Simulação de Gestão Empresarial, Simulador Organizacional, Jogo de Gestão, Jogo de Empresas, Jogo Empresarial, Jogo de Negócios ou Business Games, se destacam como sendo um inovador instrumento didático no processo de ensino-aprendizagem, pois possuem o objetivo de levar o participante a vivenciar situações semelhantes ao real, possibilitando avaliá-la por meio da análise.

Se foi identificado que para o processo efetivo da relação entre teoria x prática é a aplicação de metodologias ativas de ensino por meio de simuladores e jogos empresariais, pois Segundo Ornellas (2008), os conceitos essenciais não podem ser absorvidos apenas pela visão analítica (teoria), faz-se necessário vislumbrar as possíveis variáveis dentro do sistema e ainda solucioná-las em uma rede de relacionamento.

Ao visualizar tal cenário, o presente artigo propõe como prática acadêmica de ensino o jogo desenvolvido, Manage With Me 1.0, a prática lúdica consiste em uma simulação realista, voltada aos processos realizados dentro de um almoxarifado, buscando desenvolver e aprimorar a capacidade e habilidade dos jogadores nas perspectivas abordadas no jogo.

O desenvolvimento do Manage With Me 1.0 partiu da necessidade de novas metodologias de ensino e contribuição para o aumento no número de jogos empresárias voltados ao almoxarifado disponível para a aplicação. O jogo consiste no desenvolvimento analítico e efetivo da tomada de decisão, gerenciamento de materiais, administração de patrimônio, métodos de armazenagem, ferramentas e metodologias aplicadas no estoque, tipos de estoque, e demais processos presentes no almoxarifado. Visando contribuir para o aperfeiçoamento do jogador e contribuir para a formação de novos profissionais com 
conhecimentos mais refinados em relação ao almoxarifado e práticas realizadas para seu gerenciamento.

\section{Metodologias ativas}

Segundo Mitre et al (2008) as metodologias ativas aplicadas devem ser apreciadas por todos participantes envolvidos. O processo de ensino-aprendizagem integra a auto iniciativa, atingindo dimensões intelectuais e afetivas, tornando-se mais duradoura e eficaz no processo de absorção do aluno.

De acordo Coll (2000), há duas especificações para a construção da aprendizagem significativa: a existência de um conteúdo de interesse significativo aos olhos do discente e a adoção de uma atitude favorável para a aprendizagem, ou seja, a atitude própria do discente permite estabelecer associações entre os elementos novos e aqueles já presentes na sua estrutura cognitiva. Diferentemente do processo de aprendizagem mecânica, na qual não se consegue estabelecer relações entre o novo e o que se foi anteriormente aprendido.

Visualizando isto, se é feita a aplicação de jogos como ferramentas didáticas, proporcionando outra perspectiva ao estudante a cerca tanto do conteúdo que o mesmo demonstra interesse como o que ele apenas aprende por necessidade. A integração de conteúdos e a interação proporcionada por metodologias ativas traz efeitos positivos notórios no processo de ensino-aprendizagem.

Segundo Mitre et al (2008) as metodologias ativas usam a problemática como estratégia de ensino-aprendizagem, com o intuito de atingir e incentivar o discente, pois frente ao problema, ele se detém, examina, reflete, relaciona a sua história e passa a ressignificar suas descobertas.

O contato com a problemática pode levá-lo ao contato com as informações e à produção do conhecimento, principalmente, com a finalidade de resolver os obstáculos identificados dentro da problemática imposta e promover o seu próprio desenvolvimento. Ao notar a aprendizagem ativa como um instrumento necessário e significativo no processo de ensino para ampliar suas possibilidades e caminhos, esse poderá exercitar a liberdade e a autonomia na realização de escolhas e na tomada de decisões. 


\section{Funções dos estoques}

Segundo Chiavenato (2005) estocar tem significado de guardar algo para uma posterior utilização, o estoque é a composição de materiais não utilizados no momento, porém serão utilizados em função de ações posteriormente. Estoques são acumulações de materiais que surgem em numerosos pontos da cadeia produtiva, servindo para suprir necessidades futuras, tornando-se fundamental para o funcionamento das organizações.

A gestão de estoques integra parte da administração nas organizações, levando os gestores a tomada de decisões relacionadas a previsão, registro e controle de materiais. Dentre os motivos para ter estoques se destacam cinco das suas funções dentro das organizações: estoque de ciclo, estoque de segurança, estoque de coordenação, estoque especulativo e estoque em trânsito.

Estoques de ciclo existem por possibilitar economia em alta escala no processo de ressuprimento. "A economia em escala é caracterizada pelo fato de que quanto maior a quantidade ordenada, menor é o custo de pedido por unidade do produto. " (Garcia, Eduardo et al, 2006. p.14).

Os estoques de segurança existem para proteger as organizações de incertezas como o tempo para o recebimento dos pedidos de ressuprimento, demanda dos clientes e as quantidades recebidas são exemplificações de imprevistos que podem ocorrer. Os estoques de segurança servem para evitar ocasiões inesperadas.

Estoques de coordenação são utilizados em ocasiões que a coordenação de suprimento e demanda é impossibilitada. Fatores como sazonalidade são razões para se ter esse tipo de estoque, onde um fabricante tem por exemplo capacidade máxima de 1.300 unidades/ mês, e nos primeiros meses sua demanda é de 800 , mas nos últimos meses a sua demanda é superior a 1.300, então o fabricante produzirá as unidades que excedem o limite nos primeiros meses.

Estoques especulativos existem para poder se manter seguro em relação ao preço do mercado. As empresas podem comprar produtos em alta quantidade quando se é esperado aumento em seus valores em um espaço curto de tempo, assim garantindo uma economia e os estoques em transito, "estoques em transito são estoques ao longo dos canais de distribuição, existentes em razão da necessidade de se levar um item de um lugar para outro" (Garcia, Eduardo et al, 2006. p.15) 


\section{Custos relacionados a gestão de estoques}

Segundo Garcia (2006), os principais custos na gestão de estoques podem sem divididos em três áreas de foco: custos de pedido, custos de manutenção de estoques e custos de falta. Custos de pedido diz respeito a ordens de ressurgimento, podendo ser preços fixos e variados. Custos variáveis são os de pedido de compra, que são variáveis dependendo de quantas unidades são adquiridas na compra, já o preço fixo é por exemplo o frete, recebimento, inspeção dentre outros.

Os custos de manutenção são referentes a quantidade de tempo gasto com materiais estocados e a sua quantidade. Já os custos de falta são incorridos quando não se tem estoque suficiente para atender a demanda dos clientes em um certo instante de tempo, obtendo como consequência a perda de vendas, deterioração de imagem dentre outras.

\subsection{Posicionamento dos estoques}

Os estoques podem estar presentes em certas etapas do processo de atendimento do cliente como estoques de matéria prima, semiacabados e finalizados. Os níveis de estoque podem variar, dependendo das características de cada operação e do tempo que os clientes se dispõem tempo para esperar para ter suas necessidades atendidas. A figura 1 ilustra algumas situações.

Figura 1 - Tempo de processos e tempo do cliente.

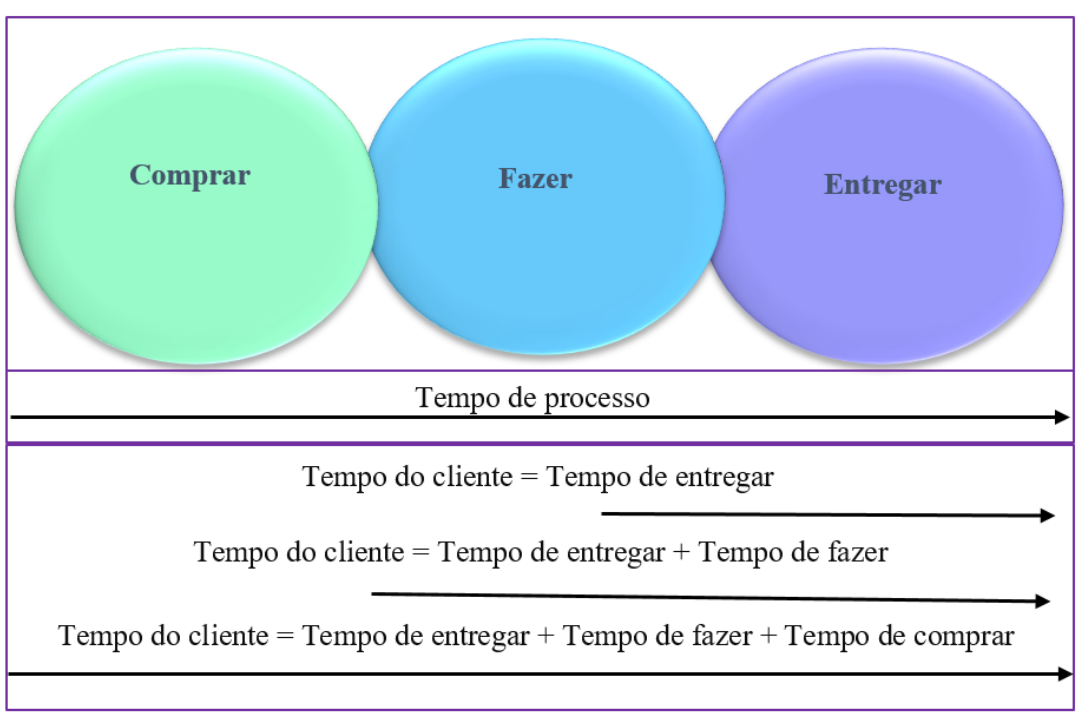

Fonte: Autor (2020). 
Se o tempo do cliente for inferior a soma dos tempos de entregar e fazer, significa que a empresa deve operar com a lógica do make-to-stock (MTS), ou seja, são utilizados estoques de produtos acabados. Se o tempo do cliente é superior à soma dos tempos de fazer e entregar significa que a lógica que se é utilizada é make-to-order (MTO), onde a empresa só necessita manter estoques de matérias primas e dar início ao processo de produção somente quando as ordens dos clientes forem emitidas.

Há casos extremos onde o tempo do cliente é superior que todo o tempo do processo. Neste caso geralmente se é utilizada a logica engineer-to-order (ETO), onde não se há necessidade de se manter estoques em processo nenhum. Existem também outros casos, as logicas apresentadas podem se estender a toda cadeia de suprimentos, variando de elo para elo e de como cada um trabalha.

\section{Gestão de estoques}

A gestão de estoques está diretamente ligada com a necessidade de integração das áreas correlacionadas a área de estoques, como por exemplo o setor de compras e os fornecedores. Desse modo, uma gestão bem realizada contribui de forma prática e positiva para todos os envolvidos nessa cadeia. Ching (2011) define gestão de estoque não apenas como um meio de reduzir custos, mais se colocada em prática como um conceito integrado a gestão de estoques se torna uma ferramenta de estratégia fundamental para a sobrevivência do negócio.

A gestão de estoque realizada sem planejamento ou executado com falho em suas etapas por meio do arranjo físico ou disponibilidade de equipamentos, são refletidos de modo negativo nos resultados das organizações, principalmente em prazos de entrega de produtos ou na disputa acirrada com a concorrência. Em contrapartida a gestão de estoque executada com exímio em todas as suas etapas pode ocasionar um efeito positivo surpreendente para a Organização.

\section{Controle de estoques}

Segundo Gomes (2004), o controle de estoques deve ser realizado em conjunto com a administração de transporte e armazéns. E deve-se optar pela redução dos níveis de estoque por motivo de fatores como maior diversidade de produtos, maior número de clientes a serem atendidos, alto custo oportunidade de capital e crescente foco gerencial no controle dos custos variáveis. Diante disso, devem ser observados os conceitos de demanda puxada e empurrada, just-in-time, kanban, curva $A B C$ dentre outros. 


\section{Fundamentação teórica}

\subsection{Produção puxada e empurrada}

A produção puxada, do inglês "pull system" é um sistema de produção onde cada ciclo da fabricação "puxa" a etapa do processo anterior, na qual a produção se inicia a partir da demanda dos clientes para somente após ela ser produzido o produto desejado. Dessa maneira só havendo produção se houver demanda.

Segundo Moreira (2017) a produção empurrada consiste na ideia de produzir os produtos antes para que ao haver necessidade de compra disponibiliza-los, onde são "empurrados" pelo fluxo de demanda. Já na produção puxada, não se há produção sem demanda

\subsection{Just in time (JIT)}

“O JIT não é um sistema clássico de produção e, na verdade, nasceu com premissas totalmente diferentes. Nele busca-se por uma produção suavizada, produzindo sempre o produto certo (ou parte de um produto) na hora certa. " (MOREIRA, 2017) O grande objetivo desse meio de produção é a eliminação de desperdício, levando a melhoria contínua da produtividade e qualidade dos produtos. Os comandos para a produção JIT se iniciam no término da linha de produção, com a última estação de trabalho; ou de modo alternativo, se inicia com o cliente.

Segundo SUGIMORI, Y. et al, a produção just-in-time é um método pelo qual o lead time é grandemente reduzido mantendo-se a conformidade com as mudanças "todos os processos produzem as peças necessárias no tempo necessário e têm de entregar apenas o estoque mínimo necessário para manter os processos juntos ". Além disso, verificando o grau de quantidade e produção de estoque tempo de execução como variáveis de política, este método de produção revela a existência de equipamentos excedentes e trabalhadores.

\subsection{Kanban}

É um método utilizado para regular o fluxo de mercadorias tanto na fábrica quanto em fornecedores externos e clientes. Baseado na reposição automática por meio de cartões de sinal, indicando quando são necessários mais produtos. O conceito de Kanban está diretamente ligado a produção JIT. Segundo SUGIMORI, Y. et al, objetivo do Sistema Kanban é um sistema de controle de produção para a produção e produção do just-in-time. $\mathrm{O}$ 
competente uso das capacidades dos trabalhadores é o Sistema Kanban. As razões para ter implementado o Sistema Kanban são os seguintes:

- Redução da informação de processamento de custos: ele exige um alto custo de implementação, um sistema que oferece programação de produção para todos os processos e fornecedores, tal como suas alterações e ajustes por meio do controle em tempo real;

- Rápidez e precisão na aquisição de fatos: usando o próprio Kanban, gerentes de oficinas podem perceber tais fatos em constante mudança como produção e capacidade, taxa de operação e potência humana sem auxilio de um computador. Como consequecia, os dados das programações referentes à mudança são precisos;

- Melhorias: limitar a capacidade demasiada das lojas precedentes. Consiste em processos de multiestágio, onde se é mais comum a demanda pelo item (a parte) tornase progressivamente mais errática quanto mais distante o ponto do processo

\subsection{Curva abc}

Segundo Viana (2010) A metodologia da curva ABC, foi idealizado pelo economista, pelo engenheiro italiano, Vilfredo Pareto, em 1897, onde a ideia originou-se a partir de estudos estatísticos relacionados a renda de pessoas de diversos países. Pareto observou que uma pequena parcela da população dos países, cerca de $20 \%$ das pessoas retém a maior parte da riqueza, e cerca de $80 \%$ das pessoas contém o restante dividido entre elas.

Esse fato possibilitou o estabelecimento de um princípio segundo o qual o maior percentual da renda de um país, em torno de $80 \%$, concentrava-se nas mãos de uma pequena parte da população, cerca de $20 \%$. Esse princípio é aplicado na gestão, Segundo Slack et al. (2002), a lei de Pareto - princípio base da curva ABC - estabelece que a proporção de $20 \%$ dos itens totais contidos no estoque representa uma grande proporção de $80 \%$ do valor total em estoque.

Então pode-se utilizar esse princípio para a classificação de diversos materiais estocados de acordo com seu valor. Dessa forma, é possível que os gestores priorizem seus esforços de acordo com os produtos mais significativos.

\section{Metodologia}


O desenvolvimento do jogo Manage With Me 1.0 realizou-se por meio de 4 etapas simples: (I) busca bibliográfica (aprofundamento na temática), (II) Definição das atividades realizadas nos tipos de almoxarifados e seus segmentos presentes nos diversos processos que compõe o gerenciamento ao qual o jogo será voltado, (III) desenvolvimento do contexto lúdico na qual se insere o jogo, tais como estabelecer as metas e objetivos a serem atingidos, (IV) Verificação geral da metodologia prática desenvolvida (jogo).

A Figura 2 expõe visualmente as etapas da metodologia realizadas na pesquisa. $\mathrm{O}$ jogo exposto no presente artigo foi desenvolvido no ano de 2020, com objetivo de contribuir na área logística com foco especial no gerenciamento de almoxarifado e técnicas lúdicas presentes no processo de ensino-aprendizagem, buscando a capacitação profissional, e ainda aperfeiçoar a capacidade de visualizar melhorias contínuas, propondo aos participantes que à façam no encontrado dentro de um almoxarifado, visto a sua relevância para as organizações.

Figura 2- Metodologia

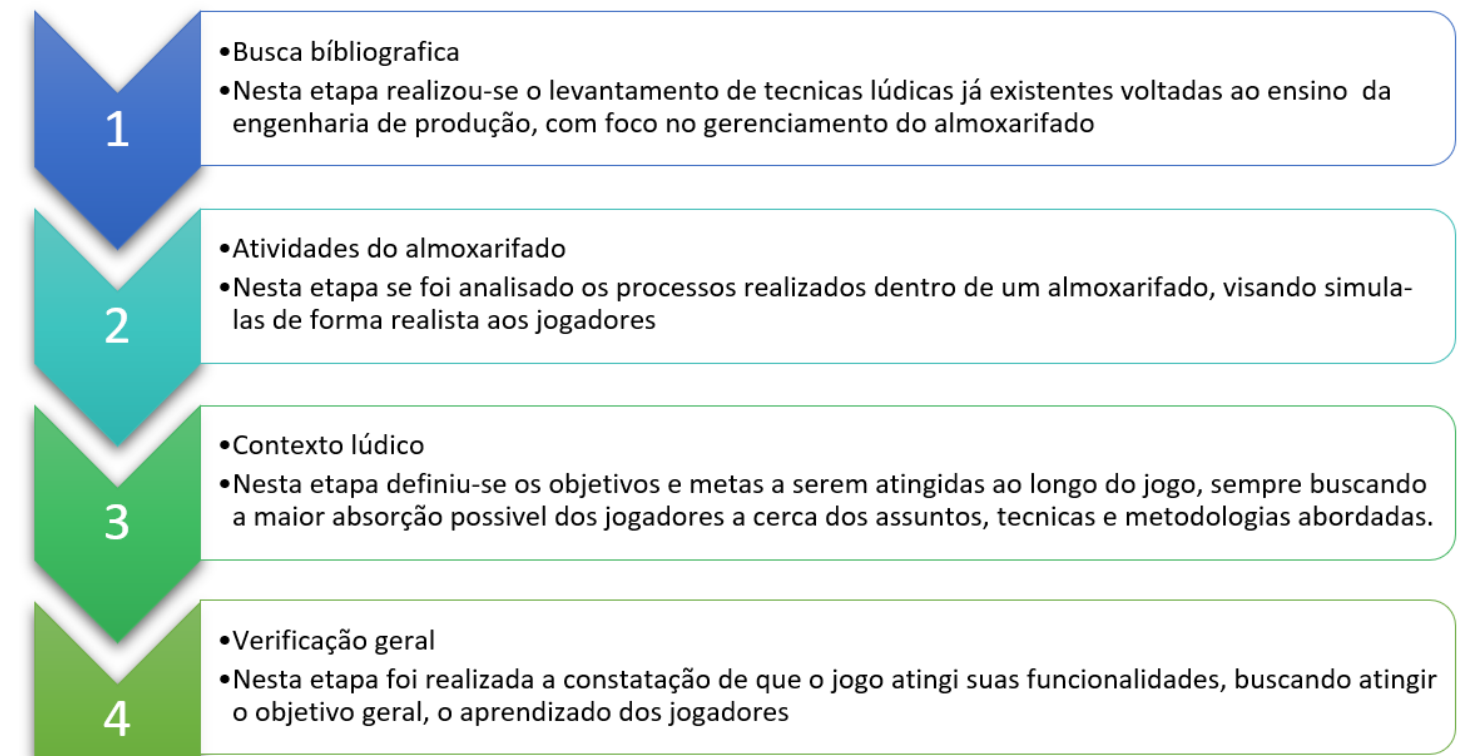

Fonte: Autor (2020).

\section{Manage With Me 1.0}

O jogo consiste no gerenciamento do almoxarifado, buscando a identificação de melhorias nos processos, correção de falhas e erros, administração de materiais, armazenamento correto, melhorias no layout disponível aos jogadores dentre outras aplicações disponíveis no jogo. 
O jogo é realizado em 3 etapas, a primeira é quando os participantes escolherão o tipo de almoxarifado em que irão gerenciar; na segunda etapa se é exposto aos "almoxarifes" (jogadores) o tipo de produção da empresa em que o mesmo trabalha, as dimensões do almoxarifado, os materiais presentes no almoxarifado, o giro dos materiais e o layout do almoxarifado juntamente aos recursos disponíveis (equipamentos de armazenagem); na terceira e última etapa, se é realizada a análise do almoxarifado pelos jogadores, na qual se é disponibilizado o total de 10 minutos para o retorno do que se foi realizado no almoxarifado pelos jogadores, havendo 3 situações impostas aos jogadores. Na figura 3 se é exposto um exemplo de almoxarifado.

Figura 3 - Almoxarifado

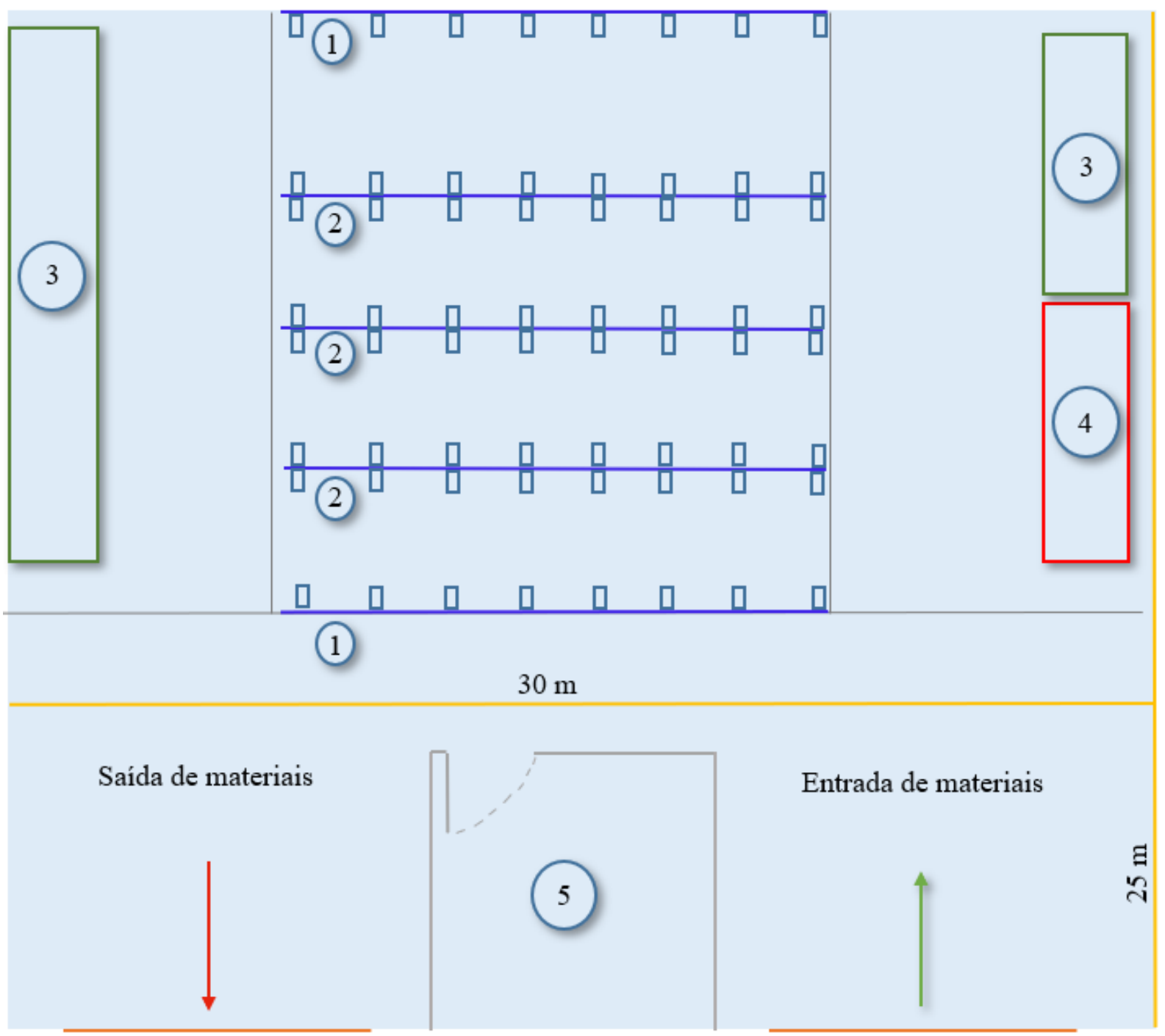

Fonte: Autor (2020).

1: Estruturas Cantillever Monofrontal

2: Estruturas Cantillever Bi-frontal 


\section{3: Estruturas Porta-pallet Convencional \\ 4: Estantes Leves \\ 5: Escritório}

Dependendo do tipo de almoxarifado o layout pode se caracterizar com outros equipamentos. Como se foi explicado acima, o jogador deve analisar o almoxarifado, propor intervenções no que ele identificar necessário, gerenciar o espaço disponível, armazenar os materiais descritos de forma correta, fazer a relação com as metodologias disponíveis para solucionar as problemáticas que lhes são impostas e apresentar as melhorias realizadas pelo jogador. Os almoxarifados disponíveis no jogo são:

- Almoxarifado de manutenção: Peças que servem de apoio a manutenção dos equipamentos e materiais de escritório utilizados.

- Almoxarifado de matéria prima: material básico que irá receber processo de transformação

- Almoxarifado de materiais auxiliares: Materiais que participam do processo de transformação da matéria prima.

- Almoxarifado geral: materiais armazenados de forma correta, respeitando suas restrições.

Recomenda-se que os materiais disponíveis em cada tipo de almoxarifado sejam indicados pelos professores ou aplicadores da técnica lúdica em questão, uma vez que seu desenvolvimento tem objetivo acadêmico. Também se indica que ao finalizar os 10 minutos disponíveis para as alterações, se haja uma análise do professor acerca das decisões e metodologias aplicadas ao longo do jogo, buscando corrigir os erros dos alunos para que os mesmos aprendam.

Sugere-se que as situações impostas aos jogadores sejam as mais próximas da realidade encontrada dentro do gerenciamento do almoxarifado, tais como armazenamento incorreto de determinado materiais, perdas de itens e sua significância para o almoxarifado (visando a aplicação da curva $\mathrm{ABC}$ ), e o armazenamento dos itens de acordo o seu giro no estoque (giro dos itens ficam a critério do aplicador da metodologia), os modelos de 
almoxarifado podem ser alterados por quem aplica a prática, possibilitando diversas abordagens.

\section{Considerações finais}

O processo de desenvolvimento da técnica lúdica Manage With Me 1.0 alcançou com o seu objetivo de proporcionar uma correlação entre a teoria e a prática inicialmente, e as metodologias de gerenciamento de almoxarifado absorvidas pelo praticante durante o seu curso, e a adoção metodológica equilibrada da ludicidade.

Executando-o de forma correta, pode-se reproduzir, sob a perspectiva da análise realizada do participante, a exploração das habilidades gerenciais dos jogadores, tal como a associação de conceitos aprendidos (teórico e práticos) sobre a gestão de materiais e demais conceitos absorvidos ao longo do curso.

A aplicação das ferramentas lúdicas como jogos associadas ao processo de ensinoaprendizagem possui potencial significante, que na atualidade, é essencial, devido à escassez de ferramentas metodológicas utilizadas como recursos educacionais voltados aos cursos de engenharia de produção e demais áreas voltadas ao mesmo eixo educacional.

A fácil associação dos conceitos aprendidos somados à metodologia ativa em questão (Manage With Me) garante que a sua aplicação proporcione tanto novos conhecimentos relacionados ao gerenciamento do almoxarifado, como em sua profundidade. Por tanto a produção desse jogo contribui com o aumento do acervo atual limitado de meios ativos de ensino disponíveis para a área de logística e seus segmentos.

O dinamismo presente na ferramenta ativa possibilita novas modificações futuras visualizando o aperfeiçoamento continuo do jogo proposto no presente estudo, por se tratar de uma ferramenta que busca impor aos jogadores situações para que os mesmos a analisem proporcionando melhorias no almoxarifado trabalhado pelo aplicador, se torna um jogo flexível, podendo integrar futuramente novas disciplinas que estejam dentro da grade curricular do grupo de discentes que os joguem, possibilitando sua utilização em outras áreas.

\section{Referências}

ARAÚJO, Daniel Almeida de. Gestão de estoques: controle e movimentação de materiais em um almoxarifado. 2018. 


\section{BARBOSA, A. F.; SILVA, FH dos S.; DE ASSUNÇÃO, M. V. D. PANORAMA DOS}

MODELOS DE JOGOS NA ÁREA DE LOGÍSTICA EXISTENTES NO BRASIL E NO MUNDO.

CHIAVENATO, Idalberto. Administração nos novos tempos. Elsevier Brasil, 2005.

CHING, Hong Yuh. Gestão de Estoque na Cadeia de Logística Integrada: Supply Chain. $4^{\circ}$ ed. São Paulo: Atlas, 2010.

Coll C. Psicologia e currículo: uma aproximação psicopedagógica a elaboração do currículo escolar. São Paulo: Ática; 2000.

GARCIA, Eduardo et al. Gestão de estoques: otimizando a logística e a cadeia de suprimentos. Editora E-papers, 2006.

GOMES, Carlos Francisco Simões. Gestão da cadeia de suprimentos integrada à tecnologia da informação. Cengage Learning Editores, 2004. just-in-time and respect-for-human system. The International Journal of Production.

MITRE, Sandra Minardi et al. Metodologias ativas de ensino-aprendizagem na formação profissional em saúde: debates atuais. Ciência \& saúde coletiva, v. 13, p. 2133-2144, 2008. MOREIRA, Daniel Augusto. Administração da produção e operações. Editora Saraiva, 2017. ORNELLAS, Alander; ORNELLAS, Renato de Campos. Jogos de empresas: criando e implementando um modelo para a simulação de operações logísticas. Revista Produção Online, v. 8, n. 2, 2008

Research, v. 15, n. 6, p. 553-564, 1977.

SUGIMORI, Y. et al. Toyota production system and kanban system materialization of VIANA, J. J. Administração de matérias: Um enfoque prático. São Paulo: Atlas, 2010 in 